\title{
Molar Uprighting Using A Cantilever Spring
}

Vasu Murthy Sesham ${ }^{1}$, Pavan Kumar Mamillapalli², Praveen Kumar Neela ${ }^{3}$, Shiva Prasad Mandaloju ${ }^{4}$, Sreekanth ${ }^{5}$

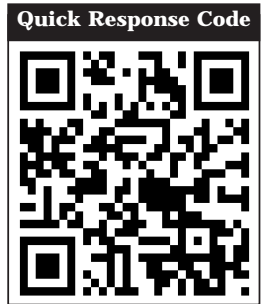

doi: $10.5866 / 2016.8 .10255$

${ }^{1}$ Professor \& HOD

2Professor

${ }^{3}$ Reader

${ }^{4} \ltimes 5$ Senior Lecturer

Department of Orthodontics,

Kamineni Insitute of Dental Sciences, Narketpally.

\section{Article Info:}

Received: October 10, 2016

Review Completed: November 11, 2016

Accepted: December 12, 2016

Available Online: December, 2016 (www.nacd.in) (c) NAD, 2016 - All rights reserved

\section{Email for correspondence:}

vasuortho@gmail.com

\begin{abstract}
:
Molar uprighting is an important adjunctive treatment in orthodontics: repositioning the tilted molar eliminates the potentially pathologic condition and simplifies the ultimate restorative procedure. A typical case of unilateral mesially tilted mandibular molar is illustrated, with uprighting spring as a treatment option and different treatment modalities for uprighting molars are discussed.
\end{abstract}

Key words: Tilted mandibular molar, Uprighting spring.

\section{INTRODUCTON}

The early loss of primary molars or permanent first molars is a routine problem in the orthodontic clinic and results in mesial inclination of the first or second and third molars, depending on the extracted or missing tooth. Mesial inclination favors the appearance of vertical bone defects and infra-osseous pockets in the mesial region of molars, distal migration of premolars, extrusion of the antagonist molar, premature contacts in centric relation, occlusal interferences during lateral and protrusive movements, in addition to, it is difficulty in prosthetic adaptation when the inclination is excessive. ${ }^{1}$

Molar uprighting into its correct position leads to the normalization of functional and periodontal occlusion situation, enabling the roots to be positioned perpendicular to the occlusal plane so that they are better able to resist to occlusal forces, in addition to facilitating the plane of insertion of the prosthesis parallel to the long axis of the tooth.

Molar uprighting can be done either by distal crown movement or mesial root movement. 
Uprighting by distal crown movement leads to increased space for a bridge pontic or implant, whereas uprighting the molar by root movement reduces space and might eliminate the need for a prosthesis, but this tooth movement can be very difficult and time consuming. ${ }^{2}$

Several methods for molar uprightning have been described which includes a continuous flexible rectangular $\mathrm{NiTi}$ wire, auxiliary uprighting spring (sectional) made of $17 \times 25$ beta-Ti wire without a helical loop or $17 \times 25$ steel wire with a loop for severely tipped molar. The mesial arm of the uprighting spring lies in the vestibule before engagement, and the spring is activated by lifting the mesial arm and hooking it over a stabilizing wire in the canine and premolar brackets. Because the force is applied to the facial surface of the teeth, an auxiliary uprighting spring tends not only to extrude the molar but alsoto roll it lingually, whileintruding the premolars and flaring them buccally. To counteract this side effect, the uprighting spring should be curved buccolingually so that when it is placed into the molar tube, the hook would lie lingually to the archwire prior to activation. ${ }^{1,2}$

A single "T-loop" sectional archwireof $17 \times 25$ stainless steel or $19 \times 25$ beta titanium wire can be effective if small amount of mesial movement is required preventing opening too much of space. ${ }^{2}$

Uprighting of molar using NiTi springs, derived from the setups, with customized resin bases were successfully treated using mini-implants between first and second premolars for indirect anchorage. ${ }^{3,4}$

With the advent of use of mini-screws as anchorage, molar uprighting procedures have become simpler, with more predictable results and better control of undesirable effects. Several other methods are placing a tipback cantilever spring made of $17 \times 25$ TMA wire, de-impacting spring, push coil spring from first to second molar, bonded attachment to second molar, crossed tipback springs made of $17 \times 25$ inch TMA wire. ${ }^{5-7}$

The present case mentioned here is of a mesially inclined lower second molar which is treated with the help of an uprighting spring made of $17 \times 25$ TMA wire.

\section{CASE REPORT}

A 17 year old male patient had reported to the department of orthodontics and dentofacial orthopaedics, kamineni institute of dental sciences with a complaint of forwardly and irregularly placed upper and lower front teeth (Figure 1). Clinical and radiographic examination was carried out with a diagnosis of Angles Class I malocclusion with bimaxillary dentoalveolar protusion and crowding in the upper and lower anteriors. On examination mesially tilted mandibular second molar was also found on lower left quadrant (Figure 2). So uprighting of second molar is performed before aligning and levelling of arches.

\section{TREATMENT PLAN}

1. Uprighting of 37 using an uprighting spring.

2. Extraction of all first premolars $(14,24,34,44)$ for correction of crowding and proclination and extraction of 38 for uprighting of 37.

3. Levelling and aligning of both the arches.

4. Followed by finishing and settling of the arches.

\section{TREATMENT PROCEDURE}

The uprightinog spring was fabricated using $17 \times 25$ Titanium-Molybdenum alloy arch wire (Figure 3). A double molar tubeis used for first molar so that the mesial arm of the spring fits into the accessory tube. For anchorage purpose a soldered lingual arch was given from first molar of one side to the other and bucally $17 \times 25$ sectional stainless steel wire was placed between second premolar and first molar $(35,36)$.

The mesial arm of the spring was incorporated into the auxillary slot of first molar tube. A perpendicular bend was given mesial to first molar tube and a small hook was incorporated at the end of the spring to engage the elastic chain to prevent counter moment. The spring was activated by means of tipback bend in the segment that is inserted into the second molar tube and a NiTi open coil spring is placed between 36 and 37 in the distal arm of the spring (Figure 4 and 5). To potentiate the tipping movement of the root in the mesial direction, a elastic chain is inserted between the second molar hook and the wire which is bent downwards from 

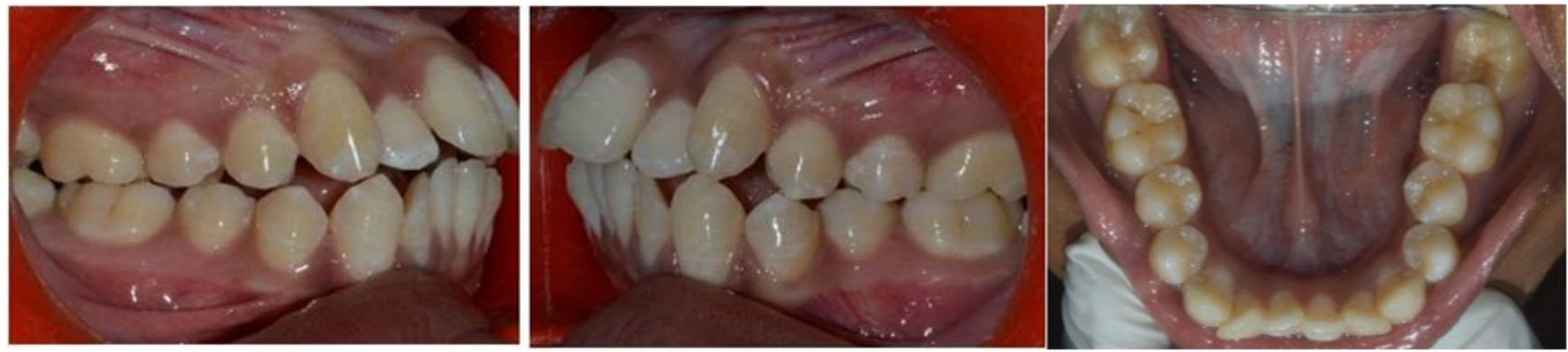

Figure 1: Pretreatment intraoral photographs showing forwardly and irregularly placed upper and lower front teeth

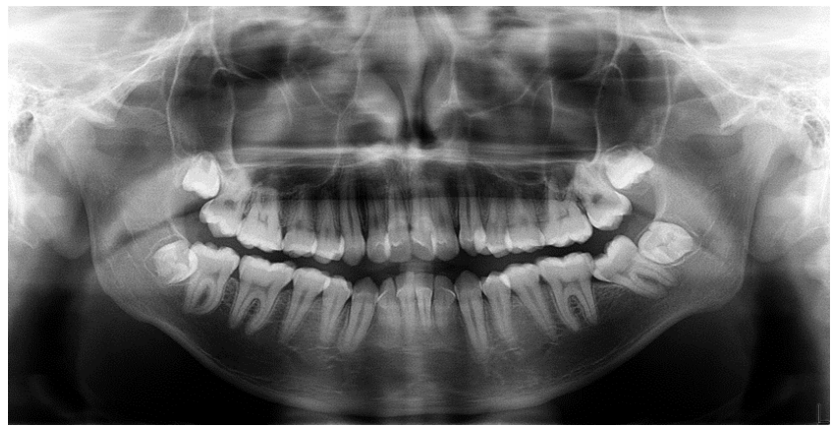

Figure 2: Pre-treatment OPG showing mesially tilted mandibular second molar in the lower left quadrant

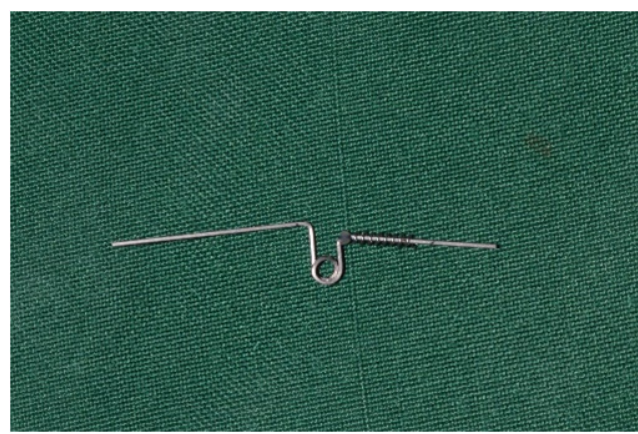

Figure 3: Uprighting spring with niti coil spring

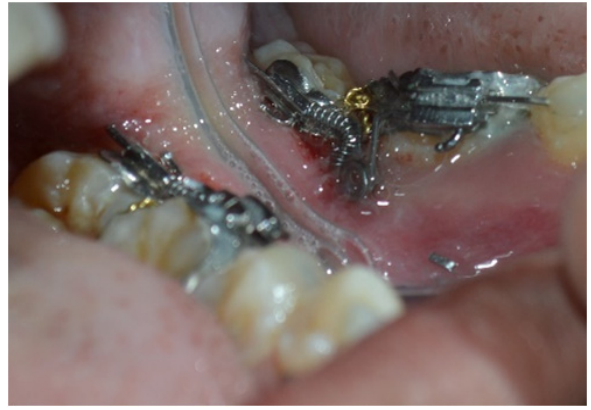

Figure 4: Appliance inserted in place

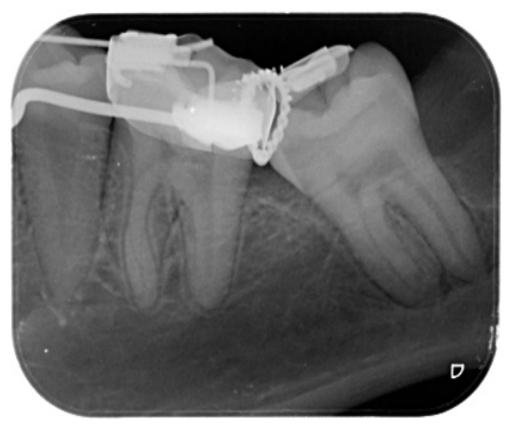

Figure 5: IOPA showing uprighting spring

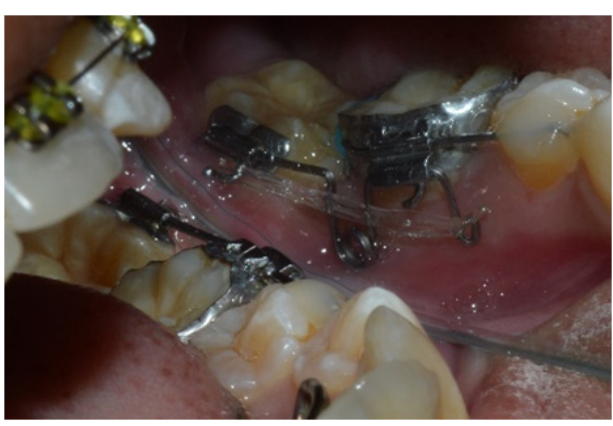

Figure 6: E-chain placed for activation of spring

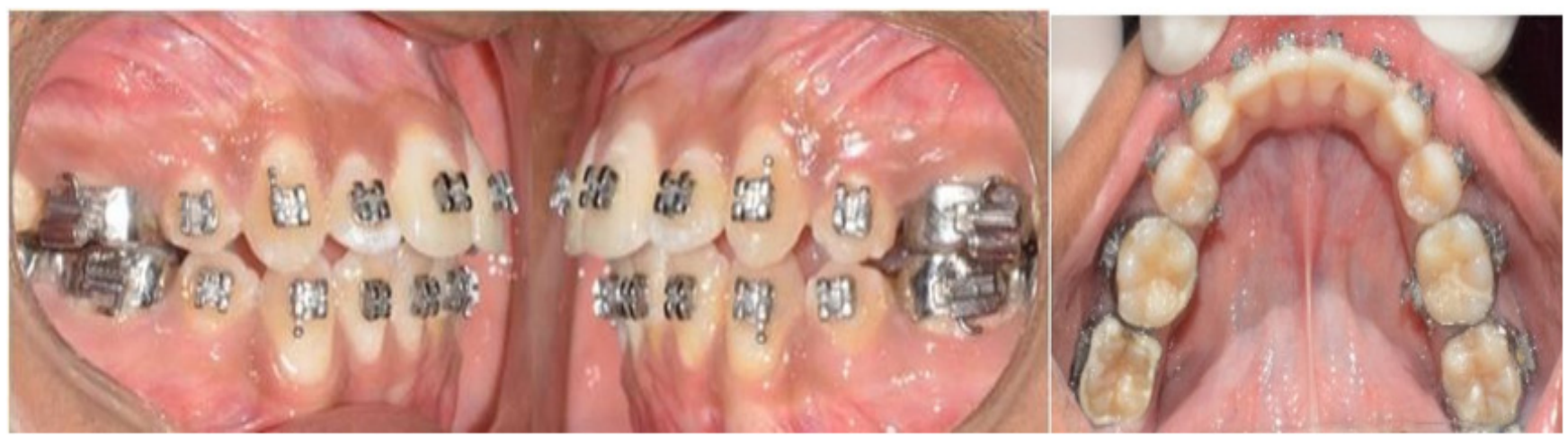

Figure 7: Post-treatment intraoral photographs. 
the mesial end of the uprighting spring (Figure 6). Molar uprighting is achieved in six months (Figure 7).

\section{DISCUSSION}

In the literature there are many devices used for molar uprighting, however, with some deficiency in control from the mechanical point of view.

In the present articlea special type of uprighting spring is used for molar uprighting. The spring must be fabricated of a rectangular cross section wire for better three-dimensional control. Stainlesssteel or titanium-molybdenum alloy ire may be used. The choice of the alloy depends on the flexibility demanded by the case, the titanium-molybdenum alloy is the wire of choice for periodontally compromised teeth as it releases more gentle forces in cases of teeth with severe mesial inclination, and when only a small quantity of wire is used for fabricating the spring. ${ }^{8,9}$

Fabrication of the helical loop provides greater flexibility, in addition to performing a fundamental function when opening movements are necessary, or performing a fundamental function when movements of opening or closure of spaces is required. $\mathrm{NiTi}$ open coil spring favours distal movement of molar. ${ }^{10}$

Tipback activation of the segment that inserts into the molar tube is performed, causing a distal moment to act on the crown and a mesial moment on the root. Space opening will be done by placing a separator between first and second molars. ${ }^{7,11}$

To potentiate mesial movement of the molar root, a vertical hook is fabricated on the mesial segment of the spring beyond the molar tube to which elastic chain is attached. The function of this hook is to minimize the extrusive effect, increase the effect of molar uprighting, and traction of the molar in the mesial direction. This will depend on the vertical length of this hook and the result of the forces applied.

The height of the hook onto which the elastic chain is placed is the factor responsible for molar extrusion control; the longer the hook, the greater the moment of mesial rotation of the root.

\section{CONCLUSION}

The use of this uprighting spring incorporating helix and a open coil spring is a simple and effective method for molar uprighting. Accurate three dimensional movement of the tooth was achieved. In addition, oral hygiene and patient comfort were maintained with this simple system.

\section{REFERENCES:}

1. Ruellas A, Pithon M, Santos R. Miniscrew-supported coil spring for molar uprighting: Description. Dental Press J Orthod 2013; 18(1):45-9.

2. Proffit WR, Fields HW, Sarver DM. Contemporary orthodontics. $5^{\text {th }}$ edition. St.Louis: Mosby, Inc; 2000.

3. Kim M, Minji K, Chun Y, Molar uprighting by a nickeltitanium spring based on a setup model. Am J Orthod Dentofacial Orthop 2014; 146:119-23.

4. Sohn BW, Choi J H, J ung SN, Lim KS. Uprighting mesially impacted secondmolars with miniscrew anchorage. J Clin Orthod. 2007; 41(2):94-7.

5. Sinha P.K; Nanda R.S; Bazakidou, E: “Uprighting fully impacted second molars, J Clin Orthod 1995; 29:316-8.

6. Rubenstein B.M: "Uprighting second molars with direct bonding."J Clin Orthod 1975; 9:377-8.

7. Frank J. Weiland, Hans-Peter Bantleon, Helmut Droschl. Molar uprighting with crossed tipback springs. J Clin Orthod 1992; 1-7.

8. Miao YQ, Zhong $\mathrm{H}$. An uprighting appliance for impacted mandibular second and third molars. J Clin Orthod 2006; 40(2):110-6.

9. Sawicka M, Racka-Pilszak B, Rosnowska-Mazurkiewicz A. Uprighting partially impacted permanent second molars. Angle Orthod 2007; 77(1):148-54.

10. Monica Sawicka, Bonga Racka P, Anna RM. “Uprighting partially impacted permanent second molars. Angle Orthod 2007; 77(1):148-54.

11. Po-Sung Fu, Chern-Hsiung, Yi-Min Wu, Ching-Fang et al . U prighting impacted mandibular permanent second molars with the tip-back cantilever technique cases report. J Dent Sci 2008; 3(3).

12. Gracco A, Lombardo L, Cozzani M, Siciliani G. Uprighting mesially inclined mandibular second molars with a modified U prighter J et. J Clin Orthod 2007; 41:281-4. 